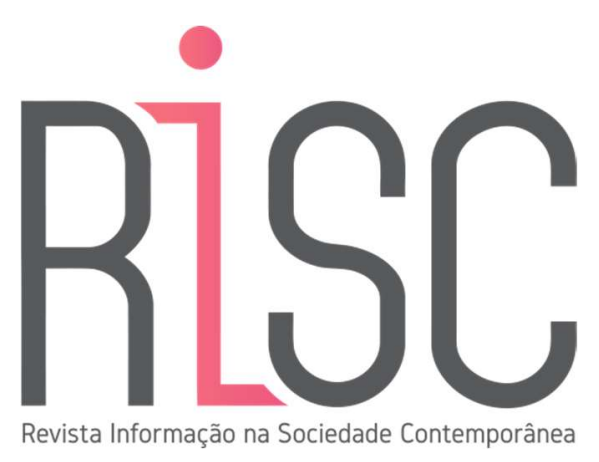

\title{
ACESSIBILIDADE INFORMACIONAL À PESSOA COM DEFICIÊNCIA VISUAL ATRAVÉS DO LIVRO FALADO
}

\author{
Grasielle Lopes Menezes da Fonseca \\ Mestra em Diversidade e Inclusão \\ Instituto Benjamin Constant, Rio de Janeiro, RJ, Brasil \\ (D) https://www.orcid.org/000-0002-5080-7115 E-mail: grasi.lopes83@gmail.com \\ Neuza Rejane Wille Lima \\ Professora Titular \\ Universidade Federal Fluminense, Niterói, RJ, Brasil \\ https://www.orcid.org/0000-0002-5191-537X E-mail: rejane lima@id.uff.br
}

Submetido em: 16-07-2020 Reapresentado em: 28-10-2020 Aceito em: 09-11-2020

\section{RESUMO}

As pessoas com deficiência visual precisam ser atendidas com recursos que contemplem os processos educacionais, culturais e políticos e, assim, é fundamental que se desenvolvam estratégias para que essas pessoas se tornem cidadãs críticas, comprometidas e atuantes em uma sociedade democrática, independente da deficiência. O estudo tem como objetivo elaborar, validar e distribuir o Manual de Produção do Livro Falado para orientar a gravação de textos em áudio, visando traçar orientações aos professores e profissionais da educação inclusiva. O Manual trará uma orientação atual e consonante com a utilização apropriada pelo usuário do produto, a pessoa com deficiência visual. A metodologia deste estudo foi qualitativa, a partir de investigação bibliográfica, histórica, documental e de campo. O Manual foi validado por meio de questionário, respondido por 12 participantes de três Oficinas de 
Gravação Digital de Livros em Áudio oferecidas no Instituto Benjamin Constant entre 2018 e 2019. O Manual produzido está disponibilizado gratuitamente em formato digital PDF em plataformas online. Esses produtos agregam experiência às perspectivas da diversidade e inclusão na área da deficiência visual e são fundamentais para o desenvolvimento de um trabalho cada vez melhor com recursos de tecnologia assistiva.

Palavras-chave: Deficiência visual. Audiolivro. Tecnologia Assistiva. Acessibilidade informacional

\section{INFORMATIONAL ACCESSIBILITY FOR PEOPLE WITH VISUAL DISABILITIES THROUGH THE SPOKEN BOOK}

\section{ABSTRACT}

People with visual impairments need to be assisted with resources that include educational, cultural, and political processes. Therefore, it is essential that strategies are developed so that these people become critical citizens, committed and active in a democratic society, regardless of the disability. The study aims to develop, validate, and distribute the Spoken Book Production Manual to guide the recording of texts in audio to outline guidelines for teachers and professionals of inclusive education. The Manual will provide a current and consonant orientation with the appropriate use by the user of the product. The methodology of this study was qualitative, based on bibliographical, historical, documentary and field research. The Manual was validated through a questionnaire, answered by 12 participants from three Digital Audio Book Recording Workshops offered at the Benjamin Constant Institute between 2018 and 2019. The produced Manual is available for free in digital format at some online platforms. These products add experience to the perspectives of diversity and inclusion in visual impairment and are fundamental to the development of an increasingly better work with assistive technology resources.

Keywords: Visual impairment. Audiobook. Assistive Technology. Information Accessibility

\section{INTRODUÇÃO}

Vivemos em um mundo em constantes transformações em vista de uma sociedade mais justa, menos preconceituosa e socialmente democrática, tendo em vista que a perspectiva de uma pessoa com deficiência visual deve passar pelo amplo acesso a toda e qualquer informação através, principalmente, de tecnologias assistivas (ARAÚJO, 2017; FONSECA; LIMA, 2019; FONSECA, 2020). 
A Lei 13.146 de 06 de julho de 2015, que institui a Lei Brasileira de Inclusão (LBI) da Pessoa com Deficiência se destina a garantir e a dar condições de igualdade, para que a pessoa com deficiência possa exercer seus direitos e a liberdade fundamental, promovendo sua inclusão social. Para possibilitar essas ações é imprescindível oferecer meios de acessibilidade (BRASIL, 2015).

Os recursos tecnológicos assistivos, como o Livro Falado, são meios eficazes para atender aos desafios educacionais especializados destinados às pessoas cegas ou com baixa visão e às exigências de acessibilidade da LBI (ARAUJO, 2017; BRASIL, 2015).

Com o advento da Lei 9.610/1998 que altera, atualiza e consolida a legislação sobre os direitos autorais, em seu item d, inciso I, Art. 46, sabemos não constituir ofensa aos direitos autorais a reprodução de obras literárias, artísticas ou científicas para uso exclusivo de pessoas com deficiência visual com distribuição gratuita e sem fins lucrativos (BRASIL, 2014; FONSECA; LIMA, 2019; FONSECA, 2020).

Consonante às informações do Ministério da Ciência, Tecnologia, Inovação e Comunicações, no Portal Brasil consta que “(...) a tecnologia assistiva serve para proporcionar ou ampliar habilidades funcionais de pessoas com deficiência" (BRASIL, 2014). Na mesma linha de pensamento, Ferreira e Miranda (2012, p. 125) afirmam que “(...) a tecnologia representa hoje um impacto na vida das pessoas e, para as pessoas com deficiências, transtornos globais do desenvolvimento e altas habilidades/superdotação, esse instrumento poderá se tornar imprescindível."

Verifica-se então que a tecnologia assistiva oferece, de fato, mais qualidade de vida, independência e inclusão social por meio da ampliação da comunicação, da mobilidade, do controle de seu ambiente, das habilidades de aprendizado, do trabalho e da íntima integração entre familiares, amigos e a sociedade como um todo (ARAUJO, 2017; FONSECA; LIMA, 2019; FONSECA, 2020).

A Tecnologia Assistiva agrega um conjunto de recursos que pode variar desde uma simples bengala até um complexo sistema computadorizado, sendo, portanto, "todo e qualquer item, equipamento ou parte dele, produto ou sistema fabricado em série ou sob medida, utilizado para aumentar, manter ou melhorar as capacidades funcionais das pessoas com deficiência" (BERSCH; SARTORETTO, 2017, p. 3).

Rev. Inf. na Soc. Contemp., Natal, RN, v. 4, 2020. 
O desenvolvimento de melhores técnicas para a produção do Livro Falado pode contribuir para um trabalho socialmente útil, colaborando na garantia de direitos da pessoa com deficiência visual. Preparar materiais pedagógicos acessíveis para a manutenção da inclusão e da participação dessas pessoas em todas as esferas sociais é um trabalho que constitui um bem ativo fundamental (FONSECA; LIMA, 2019; FONSECA, 2020). Portanto, é importante, desde que possível veicular conhecimentos na forma de livros falados para estudiosos da área ou curiosos no assunto, a exemplo dos trabalhos publicados pela Editora da UFF (LIMA; FONSECA, 2014; LIMA; GOMES; FERREIRA, 2014; LIMA, 2014) e, mais recentemente pelo Instituto Benjamin Constant (LIMA et al., 2019).

Assim, o estudo tem como objetivo elaborar, validar e distribuir o Manual de Produção do Livro Falado para orientar a gravação de textos em áudio, visando traçar orientações aos professores e profissionais da educação inclusiva.

\section{MATERIAL E MÉTODOS}

O Instituto Benjamin Constant (IBC, Rio de Janeiro, RJ) esteve de acordo com a execução desse estudo e assumiu o compromisso em apoiar o desenvolvimento do mesmo durante sua realização, tendo emitido Declaração de Anuência no dia 13 de março de 2019 (FONSECA, 2020).

Paralelamente, a pesquisa foi submetida à Plataforma Brasil ao Comitê de Ética Pública em Pesquisa (CEP - CAAE: 12124119.0.00000.5243) tendo sido aprovada em 18 de junho de 2019, por Parecer Consubstanciado (No. 3.335.548), do CEP da Faculdade de Medicina do Hospital Antônio Pedro da Universidade Federal Fluminense e do CEP da Faculdade de Medicina de Valença - Fundação Educacional Dom André (CAAE: 12124119.0.3001.5246) por Parecer Consubstanciado (No. 3.400.196).

Para avaliar a qualidade do Manual produzido, foi aplicado um questionário (Quadro 1) com 15 questões aos alunos que ativamente participaram de uma das três turmas da Oficina de Gravação Digital de Textos em Áudio que foram regularmente ofertadas no IBC (2018 e 2019). 
Quadro 1 - Lista de perguntas que foram aplicadas aos participantes das três oficinas de Oficinas de Gravação Digital de Textos em Áudio.

\begin{tabular}{|c|c|}
\hline Perguntas & Opções de Resposta \\
\hline 1. Gênero & $\begin{array}{l}\text { ( ) Feminino } \\
\text { ( ) Masculino } \\
\text { ( ) Outros }\end{array}$ \\
\hline 2. Idade? & Resposta aberta \\
\hline 3. Formação Escolar & $\begin{array}{l}\text { ( ) Ensino Médio Completo } \\
\text { ( ) Ensino Superior Completo } \\
\text { ( ) Especialização } \\
\text { ( ) Mestrado } \\
\text { () Doutorado } \\
\text { () Outros. }\end{array}$ \\
\hline 4. Atuação Profissional? & Resposta aberta \\
\hline 5. Possui formação em Atendimento Educacional Especializado & $\begin{array}{l}\text { ( ) Sim } \\
\text { ( ) Não }\end{array}$ \\
\hline $\begin{array}{l}\text { 6. Em qual ano participou da Oficina de Gravação Digital de Textos em } \\
\text { Áudio? }\end{array}$ & $\begin{array}{l}\text { ( ) } 2017 \\
\text { ( ) } 2018 \\
\text { ( ) } 2019 \\
\end{array}$ \\
\hline $\begin{array}{l}\text { 7. O que o(a) motivou a participar da Oficina de Gravação de Textos } \\
\text { em Áudio do IBC? }\end{array}$ & Resposta aberta \\
\hline 8. Já participou da elaboração de algum Livro Falado? & $\begin{array}{l}\text { ( ) Sim } \\
\text { ( ) Não }\end{array}$ \\
\hline 9. Como foi sua participação? & $\begin{array}{l}\text { ( ) Gravou } \\
\text { ( ) Editou } \\
\text { ( ) Revisou } \\
\text { ( ) Orientou }\end{array}$ \\
\hline 10. Que orientação recebeu? & Resposta aberta \\
\hline 11. O Manual que recebeu irá auxiliar seu trabalho de forma útil? & $\begin{array}{l}\text { ( ) Sim } \\
\text { ( ) Não }\end{array}$ \\
\hline $\begin{array}{l}\text { 12. Como pensa que o Manual irá facilitar a produção de Livros Falados } \\
\text { e tornar acessíveis os conteúdos para pessoas cegas e baixa visão? }\end{array}$ & Resposta aberta \\
\hline 13. Acrescentaria alguma informação a esse Manual? & $\begin{array}{l}\text { ( ) Sim } \\
\text { ( ) Não }\end{array}$ \\
\hline 14. Discorra sobre o que faltou nesse Manual? & Resposta aberta \\
\hline 15. Na sua opinião, em um conceito geral, como avalia o Manual? & $\begin{array}{l}\text { ( ) Ótimo } \\
\text { ( ) Muito Bom } \\
\text { ( ) Bom } \\
\text { ( ) Regular } \\
\text { ( ) Insuficiente }\end{array}$ \\
\hline
\end{tabular}

Fonte: Elaborada pelas autoras, 2020.

Esse questionário, contendo sete perguntas abertas e oito perguntas fechadas (Quadro 1) elaborado na plataforma Google Formulário e que foi enviado por e-mail para as turmas juntamente com o Manual e o Termo de Consentimento Livre e Esclarecido (TCLE) para que todos preenchessem e assinassem. 
Participaram dessa pesquisa pessoas maiores de 18 anos, com formação mínima de Ensino Médio Completo, que tinham cursado uma das três Oficinas de Gravação Digital de Textos em Áudio oferecidas pelo Instituto Benjamin Constant entre os anos de 2018 e 2019.

O Manual foi desenvolvido a partir de uma apostila de 21 páginas, elaborada em 2012, pela então Coordenação do Livro Falado como material didático da Oficina. No entanto, visando atender uma demanda dos alunos da turma da Oficina, desenvolveuse o Manual de Produção do Livro Falado para contribuir com conhecimento e uma formação mais atualizada e consonante com as diretrizes legais no que concernem à acessibilidade e à pessoa com deficiência.

O questionário aplicado teve como objetivo avaliar qualitativamente o Manual, para que fossem apontadas inconsistências e sugestões de melhorias em sua elaboração. Essa etapa serviu para realizar as correções necessárias para se produzir uma nova versão do Manual de Produção do Livro Falado que estará disponibilizado, gratuitamente, no blog da Associação Brasileira de Diversidade e Inclusão (ABDIn, https://abdindiversidadeeinclusao.blogspot.com/) e no site do Instituto Benjamin Constant (http://www.ibc.gov.br).

Cada Oficina de Gravação Digital de Textos em Áudio realizada no IBC comporta de 8 a 10 participantes. Os participantes da presente pesquisa cursaram as duas oficinas programadas em: 1a.) 19 de junho de 2019 (n= 7); 2a.) 30 de outubro de $2019(n=10)$. Adicionalmente, contamos com a participação de alunos da oficina de validação que foi realizada em 2018. As repostas quantitativas foram analisadas pelo programa Excel para realizar estatística exploratória e elaborar os gráficos. As respostas qualitativas foram listadas e interpretadas quanto aos seus conteúdos.

\section{METODOLOGIA}

Doze pessoas responderam ao questionário enviado. A maioria dos participantes era do sexo feminino (67\%), adultos com idade entre 46 e 60 anos (42\%), com formação preferencial em Pós Graduação (50\%), sendo um terço em Especialização latu sensu, um 
terço em Mestrado e outro um terço em Doutorado (Figura 1), ou seja, constitui um público que está no mercado de trabalho buscando melhorar sua atuação profissional com atualizações sobre os conceitos de inclusão e acessibilidade em áudio (Quadro 1).

Figura 1 - Perfil dos participantes da pesquisa $(n=12)$

Sexo dos participantes Idade dos participantes

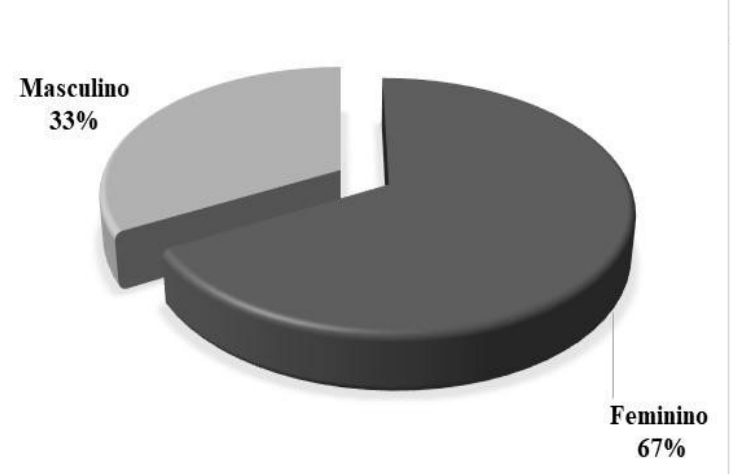

46 a 60 anos

$42 \%$

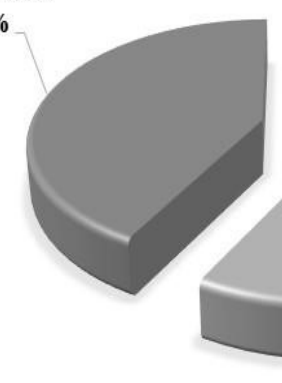

Formação dos participantes

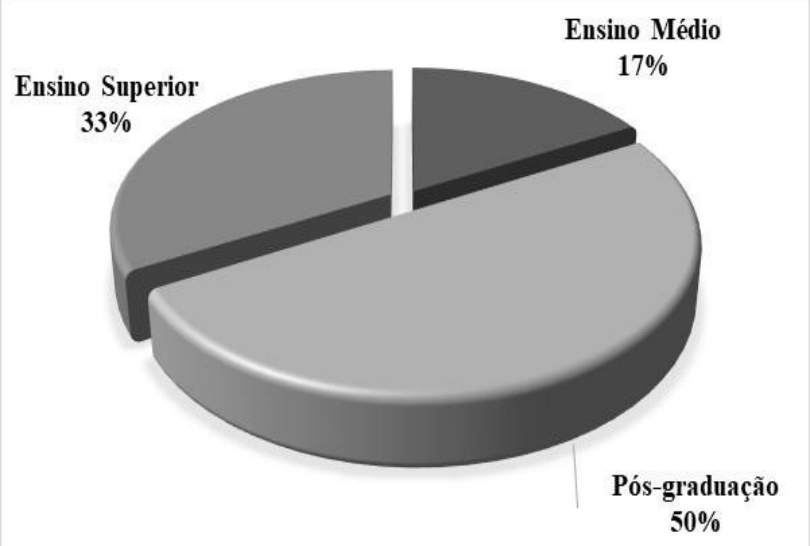

Fonte: Elaborada pelas autoras, 2020.

O público participante das Oficinas tinha, em sua maioria, Nível Superior Completo e a metade possuía Pós Graduação, o que ratifica a busca por formação continuada voltada para inclusão da pessoa com deficiência visual utilizando recursos de acessibilidade. Grande parte dos participantes (83\%) não possuía Formação em Atendimento Especializado, ou seja, não possuía formação anterior específica na área de diversidade e inclusão (Figura 1). 
Com relação a atuação profissional desse público, verificamos que dois terços se identificaram como aqueles que trabalhavam na área de Educação. As outras esferas profissionais foram identificadas como biblioteconomista, economista do lar, dramaturgia e audiovisual e consultoria/mediação. O público que mais busca esse tipo de formação continuada são pessoas que atuam em ambiente educacional em contato com alunos ou com atendimentos lúdicos e de incentivo à leitura e a cultura. A maioria (83\%) havia participado da Oficina de Gravação Digital de Textos em Áudio do Instituto Benjamin Constant (IBC) realizada no ano de 2019.

No cômputo geral, a participação dos alunos nas Oficinas de Gravação Digital de Textos em Áudio e as suas respostas revelaram que há um público interessado e preocupado em construir conhecimentos sobre materiais acessíveis em áudio, pois os resultados revelam que o Manual auxilia de forma útil no trabalho de todos os que participaram da Oficina e se atualizaram com os conteúdos e práticas disponibilizados durante sua realização (Quadro 2). Ao todo, 50\% das respostas revelaram a necessidade de adquirir novos conhecimentos; $42 \%$ citaram a necessidade de auxiliar pessoas com deficiência visual.

Quadro 2 - Respostas obtidas para a pergunta: "O que o (a) motivou a participar da Oficina de Gravação de Textos em Áudio do IBC?”

\section{Respostas}

1. "Tenho alunos cegos na escola onde trabalho."

2. "Poder ajudar pessoas, além de melhorar meu currículo para a locução."

3. "Poder gerar conteúdo acessível para pessoas com deficiência visual."

4. "Gostaria de realizar audiodescrição para cegos."

5. "O mercado está mudando, isso é importante para ajudar outras pessoas."

6. "Aquisição de novos conhecimentos."

7. "Aprimoramento para futuros trabalhos."

8. "Pesquisar e aprender novas técnicas e estratégias de gravação de Livros Falados, já que a bibliografia sobre o tema é escassa."

9. "Quero ter mais conhecimentos na área para melhorar meu trabalho."

10. "Busco me preparar para acolher bem o público deficiente visual, para que, nas atividades que desenvolvo no trabalho, possa recebê-los de modo adequado."

11. "Conhecer mais sobre a teoria e a técnica para elaborar esse recurso de inclusão em obras audiovisuais."

12. (Não respondeu)

Fonte: Elaborada pelas autoras, 2020. 
No questionário respondido pelos participantes, verificamos que apenas dois de 12 participantes $(16,7 \%)$ revelaram possuir experiência anterior na gravação de livros em áudio. Uma delas afirmou ter elaborado um Livro Falado a partir de pesquisas feitas na internet, executando todas as etapas desde a gravação, até a edição final e distribuição do material, enquanto que a outra pessoa foi orientada pelo grupo de extensão do qual participa e, assim, gravou cada página em um arquivo separado de áudio, de acordo com as orientações que recebeu, de modo a tornar o trabalho mais eficiente e organizado.

Para a pergunta: "Que orientação recebeu?" esses dois participantes responderam: (i) "Recebi algumas orientações do grupo de extensão do qual participo. Devia gravar cada página em um arquivo separado de áudio. Recebi algumas orientações contidas num arquivo em Word. Mas são orientações acordadas pelo grupo de forma a tornar o trabalho mais eficiente e organizado"; (ii) "De pesquisas na internet. Tive que fazer todas as etapas da produção". Sabe-se que a Internet é um meio de divulgação de muitos conteúdos, como identificado pela exposição das ideias do participante, que afirmou ter encontrado material online que o norteou a gravar Livros Falados.

Tendo em vista a importância de se coadunar com as mudanças tecnológicas impostas pelo tempo e pelos espaços, o Manual de Produção do Livro Falado está disponibilizado online e com livre acesso, para que o conhecimento alcance mais pessoas e, gere um despertar do olhar para a inclusão. É possível tornar o conhecimento acessível para cada vez mais pessoas.

Dos 12 participantes, 11 avaliaram que o conteúdo do Manual de Produção do Livro Falado irá auxiliar de forma útil no seu trabalho de diferentes maneiras. Além disso, esses participantes pensavam que o Manual irá facilitar de forma significativa a produção de livros falados e facilitar a acessibilidade de conteúdos para pessoas cegas e com baixa visão e relataram as informações listadas na Quadro 3 ressaltando, principalmente, a facilidade que o Manual gera na produção de novos Livros Falados. 
A partir da análise das respostas obtidas (Quadro 3), identificamos que o conteúdo do Manual será útil e dará subsídios para a produção de Livros Falados com qualidade. A maioria dos participantes avaliou que o Manual é um instrumento que oferece ferramentas para tornar conteúdos acessíveis para a pessoa com deficiência visual.

Quadro 3 - Respostas obtidas para a pergunta: "Como pensa que o Manual irá facilitar a produção de Livros Falados e tornar acessíveis os conteúdos para pessoas cegas e baixa visão?"

Respostas

1. "Vou usar na elaboração de provas para cegos na escola que trabalho."

2. "Me ajudará em meu trabalho."

3. "O Manual é bem detalhado, com ele uma pessoa com conhecimento básico conseguirá elaborar um Livro Falado."

4. "O Manual oferece instrumentos para realizar uma audiodescrição eficiente."

5. "Penso que é de fácil entendimento para as pessoas que o necessitam."

6. "Orienta a formação do conhecimento."

7. "Penso que irei acessibilizar conteúdo de uma maneira mais profissional."

8. "Conheço melhor as técnicas de aquecimento das cordas vocais e o uso do Audacity, além disso, aprendi como fazer a produção de um Livro Falado."

9. "Eu penso que o Manual esclarece bastante como utilizar o Programa Audacity, que já conhecia antes de fazer a Oficina, mas não soube utilizar corretamente."

10. "Poderei produzir material de acordo com as atividades que realizo. Quando houver um evento ou oficina onde trabalho, poderei preparar melhor um material para receber a pessoa cega ou com baixa visão, para que ela possa usufruir o máximo possível da atividade."

11. "O Manual nos ajuda a obter um rigor técnico e metodológico que possibilite um avanço na qualidade e na eficiência do material produzido. Ao utilizar as informações e orientações oferecidas, conseguimos manter um padrão de linguagem e formato."

12. (Não respondeu)

Fonte: Elaborada pelas autoras, 2020.

O Manual, portanto, além de possuir conhecimentos técnicos adequados e informações pertinentes, que esclarecem dúvidas às pessoas que buscam materiais sobre gravação de texto, utilizando a voz humana. Estes aspectos revelam que o Livro Falado oferece ferramentas para facilitar o acesso a conteúdos para $58 \%$ dos participantes e oferece conhecimento técnico adequado para 33\% dos participantes.

Metade dos participantes (50\%) atribui conceito ótimo para o Manual produzido, $33 \%$ indicaram que este é Muito Bom e o restante (17\%) que ele é Bom (Figura 2). Para a questão "Discorra sobre o que faltou no Manual" obtivemos as seguintes respostas: (i) faltou uma seção com orientações sobre como gravar: notas de rodapé; como descrever tabelas; (ii) imagens, como gravar título (se devo citar que algumas palavras 
estão em negrito, etc.) como é o jeito mais eficiente (se gravar por páginas, capítulos, etc.). Acho que um capítulo sobre audiodescrição de imagens seria muito bom, com algumas noções básicas.

Figura 2 - Respostas para a pergunta "Na sua opinião, em um conceito geral, como avalia o Manual?" $(n=12)$.

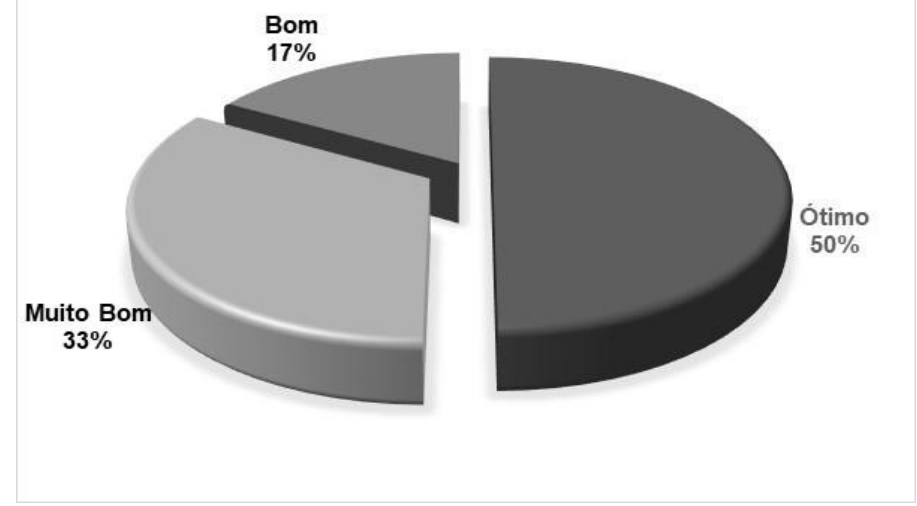

Fonte: Elaborada pelas autoras, 2020.

Outrossim, a pesquisa demonstrou que o recurso de Tecnologia Assistiva Livro Falado é produzido com qualidade tanto pela Fundação Dorina Nowill (FDN), quanto pelo Instituto Benjamin Constant. Um fato que corrobora, com a qualidade dos Livros Falados distribuídos, é a procura por diversas pessoas, físicas e jurídicas em todo o Brasil, sendo um produto desenvolvido para melhor atender às demandas das pessoas com deficiência visual.

Tanto a Fundação Dorina Nowill quanto o Instituto Benjamin Constant estão localizados nos principais polos urbanos do Brasil, São Paulo e Rio de Janeiro, respectivamente, o que favorece $o$ atendimento às pessoas que vêm de diversas localidades desses Estados em busca por serviços especializados. Além disso, ambas as instituições são referências no atendimento à pessoa com deficiência visual.

Ao analisar a estrutura de produção da FDN, tanto de Livros Falados quanto de outros serviços, compreendemos que os recursos financeiros para o desenvolvimento de outros meios de acessibilidade inovadores possuem mais investimentos, uma vez que existe uma receita financeira a partir de doações, vendas e lucros advindos das fontes de capital da Fundação, que tornam possível o desenvolvimento de novos produtos. 
Essa realidade é diferente para o Instituto Benjamin Constant, que não possui autonomia, é vinculado ao Ministério da Educação e suas ações devem ser comunicadas e autorizadas no Plano de Desenvolvimento Institucional (PDI) anual, sendo dependente, exclusivamente, de verba federal para a sua gestão. Portanto, as atividades da Coordenação do Livro Falado do IBC mantêm o desenvolvimento de sua produção com bom padrão de qualidade, mas de maneira mais lenta que a FDN, por sua configuração particular dentre os diferentes aspectos citados.

É relevante destacar que após conhecer a rica produção de materiais em áudio da FDN, concluiu-se que a Fundação e o IBC, mesmo juntos, não conseguem atender toda a produção de livros em áudio, nem de atender a todas as pessoas com deficiência visual do país. No entanto, a Lei Brasileira de Inclusão (LBI - Lei 13.146/ 2015) esclarece que a pessoa com deficiência tem direito a bens culturais em formato acessível e, que cabe ao poder público criar incentivos para a produção de livros e outros materiais acessíveis a toda a população.

Segundo Guimarães, Azevedo e Silva (2016) as dificuldades em se adequar à perspectiva inclusiva preconizada na $\mathrm{LBI}$, de maneira plena e efetiva e, que garanta a transversalidade da educação especial, são dadas devido as barreiras culturais à prática inclusiva.

Cabe ressaltar que existe um cenário favorável para que os impedimentos sejam transpostos. Há um embasamento legal e documental que esclarece e normatiza a política inclusiva. No entanto, a pessoa com deficiência também deve ser protagonista na reivindicação de seus direitos e solicitar às editoras que produzam e disponibilizem livros acessíveis, garantindo seu acesso, assim como o de qualquer outra pessoa.

A partir dessa postura, busca-se uma mudança no conceito e na cultura da produção dos mais diversos artigos de consumo acessíveis no país, transformando as perspectivas de acesso em um direito de todos no uso e desenvolvimento de mais produtos e serviços inclusivos. 


\section{DISCUSSÃO}

Para que um livro seja acessível para as pessoas com deficiência visual faz-se "necessário o investimento em tecnologias que facilite e simplifique a sua produção e distribuição" (ARAÚJO, 2017, p. 1). Essa prática dar-se-á porque "o deficiente visual enfrenta inúmeras barreiras para realizar tarefas do seu cotidiano, barreiras essas que vão desde as mais simples às mais complexas. Um desses obstáculos é a dificuldade que muitos têm de ter acesso à informação" (ARAÚJO, 2017, p. 2).

Assim, os recursos em áudio, como o Livro Falado, surgem, como um meio eficaz para atender aos desafios educacionais de produção de materiais especializados destinados às pessoas cegas ou com baixa visão e, assim, comungar com as exigências de acessibilidade da Lei Brasileira de Inclusão (BRASIL, 2015).

O Livro Falado pode fazer uso de um recurso assistivo que, normalmente, não é utilizado em Audiolivros, que é a Audiodescrição. Para Franco e Silva (2010, p. 19), “(...) a Audiodescrição consiste na transformação de imagens em palavras para que informações-chave transmitidas visualmente não passem despercebidas e possam também ser acessadas por pessoas cegas ou com baixa visão".

Um livro de história infanto-juvenil, por exemplo, traz imagens que também contam parte da história. Quando isso ocorre, um audiodescritor pode avaliar se aquela imagem precisa de tradução ou constitui apenas uma ilustração que não acrescenta ou modifica o sentido da história (FONSECA, 2020).

Ainda de acordo com registros de Franco e Silva (2010), a técnica começa a ganhar vulto no século XXI. No Rio de Janeiro, em 2003, durante uma exibição de filmes documentários no Centro Cultural Banco do Brasil, pela primeira vez, espectadores cegos foram convidados, ganharam fones de ouvido e acompanharam todo o desenrolar do filme com audiodescrição feita simultaneamente.

De acordo com Motta e Romeu Filho (2010),

A audiodescrição é um recurso de acessibilidade que amplia o entendimento das pessoas com deficiência visual em eventos culturais, gravados ou ao vivo, como: peças de teatro, programas de 
TV, exposições, mostras, musicais, óperas, desfiles e espetáculos de dança; eventos turísticos, esportivos, pedagógicos e científicos tais como aulas, seminários, congressos, palestras, feiras e outros, por meio de informação sonora. É uma atividade de mediação linguística, uma modalidade de tradução intersemiótica, que transforma o visual em verbal, abrindo possibilidades maiores de acesso à cultura e à informação, contribuindo para a inclusão cultural, social e escolar. (MOTTA; ROMEU FILHO, 2010, p. 11).

Sabe-se que os termos Livro Falado e Audiolivro têm significados distintos. De acordo com Menezes e Ribeiro (2008, p. 62), “(...) o Livro Falado apresenta apenas uma leitura branca - jargão utilizado pela comunidade -, que significa uma leitura simples, objetiva, sem maiores expressões em sua narrativa, sob o interesse de representar o livro em tinta da forma mais fiel possível."

Por outro lado, o Audiolivro segundo Menezes e Ribeiro (2008, p. 61), “(...) é um livro em áudio, no qual 'os ledores', voluntários ou profissionais contratados para esta finalidade, interpretam textos literários, científicos, ou didáticos, que, utilizando sonorizações em suas narrativas, transmitem sentimentalismo em suas apresentações."

Assim sendo, o Audiolivro é um conceito diferente do Livro Falado, constituindose, sobretudo como um recurso tecnológico pós-moderno que atende necessidades de leitura das pessoas no cotidiano, que recorrem ao mesmo devido à falta de tempo em sua rotina.

Segundo Jesus (2011), a produção do Livro Falado no Rio de Janeiro, teve início em 1970. Seu pioneiro foi o professor de música do IBC, Beno Arno Marquardt, que, junto com sua ledora, Lenora Andrade, lia e gravava diversos títulos da literatura em sua casa e os reproduzia em um tocador de fitas de rolo para seus alunos.

Esse hábito do professor Beno levou a fundação do Clube da Boa Leitura (CBL) que se transformou em uma biblioteca de livros em áudio e tem sua sede na Rua São Salvador 56, no Bairro do Flamengo, cidade do Rio de Janeiro, RJ.

O CBL atua com empréstimo de livros em áudio para pessoas cegas e com baixa visão de diversas localidades. Inicialmente, o objetivo era gravar livros em fitas cassete para pessoas com deficiência visual, com o passar do tempo, as gravações foram se 
adaptando às mudanças tecnológicas. $\mathrm{O}$ acesso às informações científicas, literárias, legais ou de outra natureza se mostrou fundamental (FONSECA, 2020).

Observamos, então, de acordo com Marques (1985), a partir da década de 1980, o surgimento das fitotecas, que são espaços dentro das bibliotecas, onde um acervo de materiais gravados em áudio era disponibilizado em fitas cassete. Quem gravava essas fitas era o denominado, ledor, ou seja, uma pessoa, normalmente voluntária, que exercia uma atividade de leitura e de comunicação à distância para um universo diversificado de usuários. Antes da fita cassete, esse ledor lia diretamente para outra pessoa, mediante releitura direta e presencial (FONSECA, 2020).

A partir do formato de leitura assíncrona por meio da fita cassete, ou seja, da leitura feita em tempo e espaços diferentes entre o emissor e o receptor, foi necessário tentar esboçar caminhos para uma padronização de técnicas de leitura gravada (FONSECA, 2020). As referidas técnicas foram publicadas em 1985 no Manual de Orientação para Leitura Gravada para Cegos que foi escrito pelo professor de História, Vitor Alberto da Silva Marques, servidor aposentado do quadro do Instituto Benjamin Constant, cego congênito.

O Manual foi destinado à então Biblioteca Regional de Jacarepaguá, hoje Biblioteca Popular de Jacarepaguá Cecília Meireles, situada na Rua Bernardino, 218, no sub bairro Praça Seca, Rio de Janeiro, RJ. Nesse sentido, visando elaborar e produzir material acessível, didático-pedagógico e especializado para a vida diária de pessoas cegas e baixa visão foram percebidas as primeiras iniciativas de se desenvolver recursos de gravação de materiais em áudio, inicialmente em fitas cassetes, em um ambiente bastante limitado tecnologicamente (FONSECA, 2020). Segundo Marques (1985, p. 1) é um recurso que "(...) contribui decisivamente para diminuir a defasagem na informação que chega aos cegos (...)"

Para Pandolfi (2003, p. 24), “A qualidade, enquanto adequação ao uso, visa garantir que o produto ou serviço em questão atenda aos anseios, expectativas e necessidades básicas (...), promovendo assim sua satisfação em relação ao produto ou serviço." 
Não foram localizados critérios de orientação e avaliação da qualidade das gravações feitas no período. Sabe-se somente que a gravação era feita por ledores voluntários, não eram locutores profissionais e muitos tinham pouca experiência na atividade. O processo de edição era analógico e rudimentar e por isso é muito comum que as gravações tenham ruídos de rua, como buzinas e apitos, tosse, gaguejos, choro de criança, latidos de cães, dentre outros ruídos, além de cortes repentinos na fala e outras interferências sonoras (FONSECA, 2020).

Sendo assim, esse estudo sugere o Manual como guia-orientador para professores e outros profissionais que buscam soluções para tornar diversos títulos acessíveis em áudio. O Manual está disponível para download no site do IBC, além de ser material didático distribuído nas Oficinas de Gravação Digital de Textos em Áudio. A publicidade do Manual também conta com divulgações em seminários, congressos, consultorias, eventos e artigos a serem submetidos a revistas, mesmo após a conclusão do estudo.

A grande parcela de pessoas com deficiência visual, de modo geral, tem acesso a serviços e recursos de atendimento especializado quase que exclusivamente nos grandes centros urbanos. Assim sendo, embora o Brasil tenha sido "o precursor no atendimento educacional integrado, (...) os serviços educacionais existentes ainda estão longe de promover a real integração e inclusão com qualidade da pessoa com deficiência no sistema geral de ensino" (BORGES, 2017, p. 161).

É nesse cenário que a integração e a inclusão se tornam possíveis, por meio do acesso a recursos tecnológicos facilitadores do processo de ensino-aprendizagem e da comunicação social. Por isso, “(...) é inegável a transformação que a tecnologia vem proporcionando na vida das pessoas e na execução de tarefas (...), é possível perceber que a evolução tecnológica caminha na direção de tornar a vida mais fácil" (FERREIRA; MIRANDA, 2012, p. 107), principalmente a vida das pessoas com deficiência e o Livro Falado se configura como parte integrante desse contexto técnico-assistivo (FONSECA; LIMA, 2019; FONSECA, 2020). 
A pessoa com deficiência sabe o que é melhor para ela e tem demandas individualizadas, que fazem parte de seu universo e, ela mesma deve apontar os caminhos com as melhores soluções para facilitar sua autonomia.

Assim, de acordo com Sassaki (2007) "nenhum resultado a respeito das pessoas com deficiência deverá ser gerado sem a plena participação das próprias pessoas com deficiência", ou seja, qualquer produção sobre a pessoa com deficiência deve contar com a sua participação e envolvimento na validação dos benefícios, facilidades ou auxílio que determinado produto propõe. Essa ideia está reunida no lema, mundialmente conhecido, "Nada sobre nós, sem nós" (SASSAKI, 2007).

A partir das contribuições dos participantes da Oficina, ao responderem um Questionário que avalia a qualidade do Manual desenvolvido, pretende-se uma melhoria, no que tange a gravação e produção de material especializado em áudio, estimulando mais profissionais a trabalharem pela educação inclusiva, tornando o ensino e seus processos mais motivadores e atrativos com o auxílio do recurso de tecnologia assistiva Livro Falado.

Pretende-se, assim, aumentar o envolvimento de pessoas cegas e com baixa visão na construção autônoma de seu conhecimento (FONSECA, 2020).

Ao corroborar para suprimir lacunas na aquisição de informações e conteúdo, desperta-se o gosto pela literatura, estimula-se o pensamento crítico e portanto, possibilita que as pessoas com deficiência visual possam ter acesso informacional tal qual as pessoas sem deficiência, o que se acredita ser a maior contribuição deste trabalho.

\section{CONSIDERAÇÕES FINAIS}

Produtos e serviços voltados para as pessoas com deficiência vêm conquistando cada vez mais espaço na sociedade, assim como diversas ferramentas e instrumentos se desenvolvem constantemente em auxílio às pessoas com deficiência visual a partir de suportes tecnológicos. 
Além disso, a luta pela inclusão concerne à oferta de um atendimento adequado a cada pessoa com deficiência, a partir da sua demanda individual específica. É, portanto, impreterível, que a oferta de atendimento especializado esteja disponível à sociedade com qualidade, de modo responsável e atento.

A valorização e o respeito à diversidade de caminhos do indivíduo humano fornecem a base e o fundamento para o desenvolvimento de um ser humano mais informado, consciente, crítico e capaz na execução de sua cidadania ao oferecer meios que permitam o gozo de direitos e a assunção de deveres dentro da sociedade, independente do recurso de acessibilidade que necessitar.

A partir da experiência dessa pesquisa, fazemos votos de enriquecimento de horizontes tanto pessoal quanto profissional do maior número de pessoas possível, ao permitir a todos um olhar mais atento para aspectos da diversidade e inclusão antes não percebidos. Essa transformação é fundamental na garantia de direitos às pessoas com deficiência visual, no desenvolvimento de produtos e ferramentas melhores, contribuindo para um mundo mais justo e equilibrado de oportunidades e acesso à informação.

\section{REFERÊNCIAS}

ARAÚJO, Aline Karoline da Silva. O livro acessível: um auxiliar no acesso à informação para deficientes visuais. Revista Informática na Sociedade Contemporânea, v.1, n.2, p. 1-20, 2017.

BERSCH, Rita; Introdução à Tecnologia Assistiva. Porto Alegre: Assistiva, Tecnologia e Educação, 2017. Disponível em:

https://www.assistiva.com.br/Introducao_Tecnologia_Assistiva.pdf Acesso em: 02 out. 2020.

BORGES, Leonídia. Aprendizagem na Diversidade. Rio de Janeiro: Ed Luminária Academia, 2017.

BRASIL. Lei no 13.146, de 06 de julho de 2015. Institui a Lei Brasileira de Inclusão da Pessoa com Deficiência (Estatuto da Pessoa com Deficiência). Brasília, DF, 2015. Disponível em: http://www.planalto.gov.br/ccivil_03/_ato20152018/2015/lei/l13146.htm. Acesso em: 10 mar. 2020. 
BRASIL. Ministério da Ciência, Tecnologia, Inovação e Comunicações (MCTI). Portal Brasil. Tecnologia Assistiva ajuda a melhorar a qualidade de vida de pessoas com deficiência. 2014. Disponível em: http://www.brasil.gov.br/ciencia-etecnologia/2010/08/tecnologia-assistiva. Acesso em: 14 maio 2018.

FERREIRA, Lavine Rocha Cardoso; MIRANDA, Arlete Aparecida Bertoldo. Experiências vivenciadas por alunos com deficiência visual em instituições de ensino superior na cidade de Uberlândia. In: SILVA, Lázara Cristina da; DECHICHI, Cláudia; SOUZA, Vilma Aparecida de (org.). Inclusão Educacional, do discurso à realidade: construções e potencialidades nos diferentes contextos educacionais. Uberlândia: EDUFU, 2012. p. 111-138.

FONSECA, Grasielle Lopes Menezes da. Manual de produção do livro falado: subsídios para a acessibilidade informacional à pessoa com deficiência visual. 2020. Dissertação (Mestrado em Diversidade e Inclusão) - Universidade Federal Fluminense, Niterói, 2020.

FONSECA, Grasielle Lopes Menezes da; LIMA, Neuza Rejane Wille. Semelhanças e diferenças entre as gravações de livros em áudio na década de 1980 e no século XXI. In: LIMA, Neuza Rejane Wille; PERDIGÃO, Luciana Tavares; DELOU, Cristina Maria Carvalho (org.). Pontos de Vista em Diversidade e Inclusão - volume 6. Niterói, RJ: ABDIn, 2019. p. 162-167.

FRANCO, Eliana Paes Cardoso; SILVA, Manoela Cristina Correia Carvalho da Audiodescrição: breve passeio histórico. In: MOTTA, Livia Maria Villela de Mello; ROMEU FILHO, Paulo (org.). Audiodescrição: Transformando imagens em palavras. São Paulo: Secretaria de Estado dos Direitos da Pessoa com Deficiência do Estado de São Paulo, 2010. p.23-42.

GUIMARÃES, Décio Nascimento; AZEVEDO, Samara Moço; SILVA, Camille Auatt da. Inclusão escolar no Brasil: o direito na prática. In: GUIMARÃES, Décio Nascimento (org.). Escola hoje: Contexto contemporâneo da Educação. Campos dos Goitacazes, RJ: Brasil Multicultural, 2016.

JESUS, Patrícia Silva de. Livros sonoros, audiolivro, audiobook e Livro Falado. 2011. Disponível em: http://www.bengalalegal.com/livros-sonoros. Acesso em: 10 mar. 2020.

LIMA, Neuza Rejane Wille. Dezoito histórias de castradores parasitários - livro falado. Niterói: Editora da UFF, v. 1, 2014. 
LIMA, Neuza Rejane Wille; FONSECA, Juliana Pipoli da. Contando a história do panda gigante - livro falado. Niterói: Editora da UFF, v. 1, 2014.

LIMA, Neuza Rejane Wille; GOMES, Suzete Araujo Oliveira.; FERREIRA, Philipe Marinho. Contando a história dos piolhos - livro falado. Niterói: Editora da UFF, v.1, 2014.

LIMA, Neuza Rejane Wille et al. Contando histórias naturais e sociais através das fezes - livro falado. Rio de Janeiro: Instituto Benjamin Constant, v. 1, 2019.

MARQUES, Vitor Alberto da Silva. Manual de orientação para leitura gravada para cegos. Jacarepaguá: Associação de Amigos da Biblioteca Regional de Jacarepaguá, 1985. $12 \mathrm{p}$.

MENEZES, Nelijane Campos; RIBEIRO, Sérgio Franklin. Audiolivro: uma importante contribuição tecnológica para os deficientes visuais. Revista Ponto de Acesso, Salvador, v. 2, n. 3, p. 58-72, 2008.

MOTTA, Livia Maria Villela de Mello; ROMEU FILHO, Paulo (org.). Audiodescrição: Transformando imagens em palavras. São Paulo: Secretaria de Estado dos Direitos da Pessoa com Deficiência do Estado de São Paulo, 2010.

PANDOLFI, Cesar. Utilização da pesquisa de satisfação de clientes como ferramenta para decisões gerenciais e melhoria contínua. Orientadora: Carla ten Caten. 2003. 185 p. Dissertação (Mestrado Profissionalizante em Engenharia) - Escola de Engenharia, Universidade Federal do Rio Grande do Sul, Porto Alegre, 2003.

SASSAKI, Romeu Kazumi. Nada sobre nós, sem nós: da integração à inclusão. Parte 2. Revista Nacional de Reabilitação, ano X, n. 58, p. 20-30, 2007. 